\title{
IS USING METAPROTERENOL SULFATE RELIABLE IN HYPERTENSION MANAGEMENT DURING THE CORONARY ARTERY BYPASS GRAFT SURGERY IN TERMS OF GRAFT PATENCY?
}

\author{
Mehmet Okan Donbaloğlu' ${ }^{1}$ Özcan Gür'², Selami Gürkan², Eylem Kuday Kaykısız \\ ${ }^{1}$ Özel Memorial Hastanesi Antalya, Turkey \\ ${ }^{2}$ Department of Cardiovasculary Surgery, Faculty of Medicine, Namık Kemal University, Tekirdağ, Turkey \\ ${ }^{3}$ Department of Emergency Medicine, Denizli State Hospital, Denizli, Turkey
}

\begin{abstract}
INTRODUCTION: Coronary artery bypass graft (CABG) surgery that is a basic revascularization method is used commonly and hypertension appears frequently during and after CABG operations. In the treatment of hypertension, metaproterenol sulfate (MS) is one of the main agents; however, the effects of this agent on grafts are not known at an adequate level. The aim of the present study was to determine whether MS could be used safely in CABG operations by examining its effects on coronary grafts.
\end{abstract}

MATERIAL AND METHODS: This cross-sectional, prospective, experimental study was conducted at a university hospital. In this study, internal thoracic artery (ITA), radial artery (RA) and saphenous vein (SV) graft materials were studied in organ bath in patients who underwent CABG surgery between 2013 and 2016. In the organ bath, $10^{-6}$ phenylephrine was added to the grafts to ensure that the ITA, RA and SV grafts contracted submaximally. Then, by adding MS with the cumulative method, the resulting relaxation results were recorded and dose-response curves were created. The $p<0.05$ was considered as significant.

RESULTS: A total of 30 patients were included in the study. The average age of the participants was 59.3 (45-81) years. Minimum 1 and maximum 6 grafts (2.96 in average) were taken from all patients. Relaxation response was formed in the ITA at a rate of $40.49 \% \pm 13.52$, in the RA at a rate of $28.41 \% \pm 9.08$ and in the SV at a rate of $23.87 \% \pm 8.36$ by adding MS with the cumulative method. In the statistical work that was done by comparing the relaxation values among the SV grafts, ITA and RA grafts, it was determined that the efficacy of MS in the SV grafts was significantly lower when compared with the ITA and RA grafts.

CONCLUSIONS: In the present study, it was concluded that the risk of developing vasospasm was low in all three grafts when MS was used in intraoperative and postoperative periods. However, in the long-term, this made us consider that better graft patency rates might be obtained. Multicenter in-vivo studies with larger patient groups are needed to support our findings.

KEY WORDS: graft surgery, hypertension management, metaproterenol sulfate

Disaster Emerg Med J 2021; 6(1): 41-47 


\section{INTRODUCTION}

In patients who have atherosclerotic coronary artery disease, methods such as stenting, balloon angioplasty and coronary artery bypass graft (CABG) surgery are known as the basic revascularization methods. CABG surgery was first used in late 1960s. The purpose in $C A B G$ operations is providing adequate blood-flow to the distal part of the heart vein where there is patency, providing blood to the ischemic myocardium in these areas, increasing the functional capacity of the patient by providing better contractions in myocardium, and helping to increase the life quality and life expectancy of the patient. Today, CABG surgery is used commonly.

A 42-year-old patient, who underwent coronary endarterectomy, received 'bypass' with saphenous vein (SV) grafts due to necessity. This anastomosis that was carried out by Johnson is considered as the first successful coronary bypass. After this period, the use of SV has become common. In the forthcoming years, the interest in it increased when it was shown that the patency rates of the internal thoracic artery (ITA) graft were higher than those of the SV grafts; and the use of ITA became $13 \%$ in early 1980s. In time, alternative arterial grafts were searched. Operations were performed in which other arterial grafts were used together with ITA, and complete arterial revascularization was obtained in this way. In our present time, ITA, radial artery (RA) and SV grafts are used commonly for CABG operations. One of the other grafts that may be used as autogenous grafts in CABG operations include gastroepiploic artery (GEA), inferior epigastric artery (IEA), splenic artery, subscapular artery, inferior mesenteric artery, lateral costal artery, and thoracodorsal artery [1]. In selecting the graft, the age and background of the patient, the location and spread of the involvement in coronary arteries, the condition of the vessel that may be used as the graft in the patient, and the opinion of the surgeon are influential. The structural and physiological characteristics of the graft that is employed in coronary artery 'bypass' operations have an important impact on the short- and longterm patency rates. If the graft spasm that occurs in the early period of the operation due to mechanical or pharmacological reasons is not resolved, it may affect the graft patency negatively in the short and long term [2]. For this reason, the effects of the pharmacological agents used must be well-known. For this purpose, the effects of the pharmacological agents that are used must also be known well. For this reason, Green suggested papaverine injection to prevent spasm in IBA [3]. In case of necessity, proper relaxing agents may be administered to improve the graft blood-flow and to reduce the long-term patency rates by reducing the damage in the graft to the minimum level. It is known that the internal thoracic artery is the most commonly used graft due to its higher patency rates compared to venous grafts.

There is a medial layer, which is the excessive response to spasm by the RA. The spread of the RA use made it possible with the resolution of the vasospasm problem. Nowadays, it is the most frequently used arterial graft after ITA [6]. In many cases, RA can be removed safely as the ulnar artery provides sufficient blood-flow. However, anomalies like the lack of ulnar artery and incomplete SPA or SPA receiving blood dominantly from the RA might occur in this respect. For this reason, the collateral circulation presence must be evaluated prior to the RA graft use. In practice, this is carried out with the Allen Test [5].

Today, the major SV continues to be the most preferred method in coronary artery 'bypass' surgery with an ITA graft in many surgical centers [6]. The easy availability of the major SV as a graft, its easy removal, and its being resistant to spasm are considered as its advantages. On the other hand, it also has some disadvantages like low patency rates, diameter mismatch between the distal and proximal ends, varicosity, development of sclerosis, and especially in patients with peripheral arterial disease, the problems related to wound healing $[7,8]$.

Hypertension occurs frequently during and after CABG operations. The increased epinephrine and norepinephrine levels are held responsible for hypertension [9]. In the treatment of hypertension, metaprolol sulfate, esmolol hydrochloride, nitroprusside sodium and isosorbide mononitrate perfusions are known to be used as the main agents; however, the effects of these agents on grafts are not known at an adequate level. Metaproterenol sulfate has selective bronchodilator and beta mimetic effects. It is very effective in controlling the intubation, bradycardia and hypertension that occur in bypass surgery during catheterization. However, it must not be used for prophylaxis. The aim of the present study was to determine whether metaproterenol sulfate could be used safely in $C A B G$ operations by examining the effects of it on coronary grafts. 


\section{MATERIAL AND METHODS}

This cross-sectional, prospective study was conducted at Namık Kemal University Hospital, Tekirdağ, Turkey. This University hospital has a capacity of 1042 beds. The daily number of application to cardiovascular surgery polyclinic is about 50 patients; and the annual number of patients undergoing CABG surgery is about 240. After the approval of the Ethics Committee of Namık Kemal University, Faculty of Medicine with the number NKUBAP.00.20. TU.13.02, and after obtaining metaproterenol sulfate that would be used in in-vitro organ bath by the team that was responsible for the study, the study was initiated. In this study, ITA, RA and SV graft materials were studied in organ bath in patients who underwent CABG surgery between January 1 , 2013 and December 31, 2016 (3 years). Written informed consent was_obtained from all the participants who were included in the study. The inclusion criteria of the study were being older than the age of 18 , having undergone CABG surgery, being a patient with ITA, RA and SV graft materials, and being volunteers to participate in the study.

The CABG operation was performed in all patients who participated in the study by providing hypothermic CPB and cardiac arrest at NKUTF Cardio-Vascular Surgery Clinic. The ITA, RA and SV were used as graft in these patients. The internal thoracic artery was removed with pedicles with the help of electrocautery and scissors.

Titanium hemoclip was used to connect the side branches. The internal thoracic artery was cut after bifurcation. The superior epigastric artery (SEA) and the musculophrenic artery (MFA) branches in the distal area were clipped. The ITA part was taken without applying papaverine on the internal thoracic artery. In all patients, after the ITA was removed and prepared for anastomosis during the operation, the distal part that was removed was used. After the SV was removed with pedicles by dissection with scissors, the saphena was taken without inflating with SF. In selecting the RA graft, first the non-dominant arm was preferred; and the Allen Test was applied to the patients to evaluate the ulnar artery collateral circulation. The RA was not excised in patients who had RA cannulation history, subclavian patency, inadequate ulnar circulation, and who needed arteriovenous fistula for hemodialysis. After the radial-ulnar artery bifurcation discrimination, and following its removal in skeletonized form by clipping its side branches as of the wrist proximal area during the operation, the remaining RA part was taken by dissecting it from the distal segment. The RA and ITA were excised with the help of cautery and scissors together with adjacent vein, fascia and surrounding fat tissue.

After the grafts were excised, they were not exposed to any vasodilator agents of any form during the preparation stage. Once they were prepared as graft, the remaining $1-\mathrm{cm}$ parts of the ITA, RA and $\mathrm{SV}$ were taken into Petri dishes that contained $+4^{\circ} \mathrm{C}$ Krebs Solution without any process. Then, they were brought to the laboratory at NKUTF Coronary Artery Surgery. The composition of the Krebs Solution (mM) was: $\mathrm{NaCl} 122, \mathrm{KCl} 5 ; \mathrm{CaCl}_{2} 1.25 ; \mathrm{NaHCO}_{3} 25$; $\mathrm{MgSO}_{4} 1.2 ; \mathrm{KH}_{2} \mathrm{PO}_{4}$ 1.0; glucose 11.5. The grafts were dissected into 2 -mm long sections by clearing the surrounding tissues in the light microscope at $22^{\circ} \mathrm{C}$ room temperature, and were suspended horizontally in the isometric transducer (FDT10-A, COMMAT, Turkey) with a plating hook in organ bath that included $10 \mathrm{ml}$ Krebs Solution aired with carbogene $\left(95 \% \mathrm{O}_{2}+5 \% \mathrm{CO}_{2}\right)$ at $37^{\circ} \mathrm{C}$; and 2 gram pre-elongation was applied. The responses were transferred to the computer through 4-channel Transducer Acquisition System (COMMAT TDA-10-A, COMMAT, Turkey) and were recorded in POLWIN97 Program. For the adjustment of the tissues, washing was carried out every 10 minutes; the pre-elongation was set at 2 grams; and 90 minutes passed in this condition. To test the firmness of the vein endothelium, acetylcholine $\left(10^{-6} \mathrm{M}\right)$ was administered to the prepared samples that were contracted submaximally with phenylephrine $\left(10^{-6} \mathrm{M}\right)$ to test whether relaxation response existed. The samples that did not yield adequate relaxation response were excluded from the study.

The parts that were prepared at the beginning and at the end of the experiment were stimulated to receive their control responses. At the end of the experiment, in the control responses, the data that were obtained in the samples that showed significant amplitude reduction compared to the initial control responses at the beginning of the experiment were excluded from the analyses. To ensure standardization in the evaluation of the responses, all the responses were calculated over the percentage in the control traces that were obtained initially.

The metaproterenol sulfate (Boehringer Ingelheim-Alupent), which was purchased with the support of the researchers, and the potassium hydrochloride (Sigma) and phenylephrine (Sigma), which 
were already present at the Cardio-Vascular Surgery Department, were used in the experiment. The molarity calculations of these substances that were needed in the experiments were adjusted by weighing at precision scale (Mettler Toledo, AB 304-5). All the agents were prepared by dissolving them in distilled water. In the organ bath, the drug injections were applied with Eppendorf adjustable pipets (10-100 $\mu \mathrm{L}, 100-1000 \mu \mathrm{L})$. In the ITA, RA and SV samples, the dose responses of the metaproterenol sulfate were taken with the cumulative method, and the dose response curves were obtained. Then, the effects of metaproterenol sulfate were examined according to the responses received.

In the organ bath, $10^{-6}$ phenylephrine was added to the grafts to ensure that the ITA, RA and SV grafts contracted submaximally. Then, by adding metaproterenol sulfate at rates that varied between $10^{-8}$ and $10^{-4} \mathrm{M}$ (the cumulative method), the resulting relaxation results were rated to the relaxation with the phenylephrine contraction to create the dose-response curves.

\section{Statistical analysis}

The Graphpad Prism 6 program was used in the analyses of the data. The concentration-response graphics were obtained with this program that included statistical analysis in it. The non-linear regression analysis (variable slope) and the one-way ANOVA were applied to the graphics. The $p<0.05$ was considered as significant in statistical analyses.

\section{RESULTS}

A total of 30 patients, $15(50 \%)$ of whom were males and $15(50 \%)$ of whom were females, were included in the present study. The average age of the participants was 59.3 (45-81 years of age). The average age of the female patients was 60.6 (45-72), and that of the males was 58 (48-81). No statistically significant differences were detected between the genders in terms of age $(p>0.05)$.

Minimum 1 and maximum 6 grafts (2.96 on average) were taken from all patients. The number of the left ITAs that were taken as graft was 30; the number of RAs was 13; and the number of SVs was 25. No grafts were taken from the right ITA. The average partial by-pass time of the cases was determined to be $55.7 \mathrm{~min}$. (27-110), and the total bypass time was determined to be $86.2 \mathrm{~min}$. (35-140).

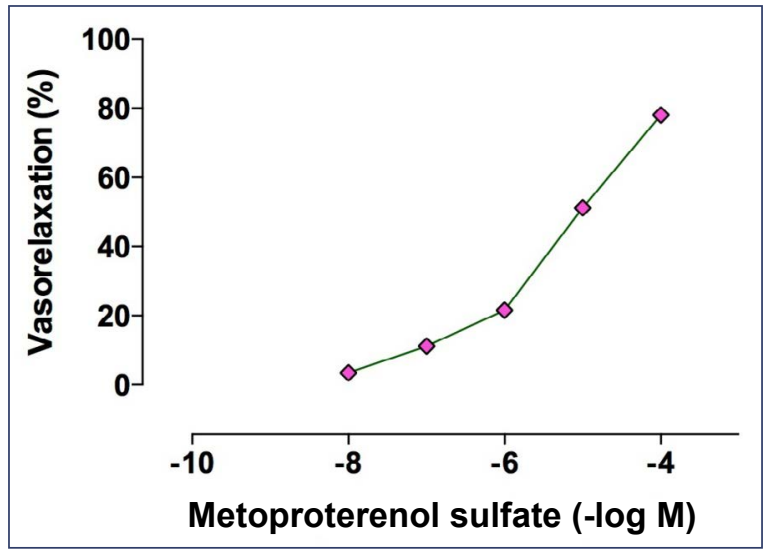

FIGURE 1. The dose-response curve for internal thoracic artery graft

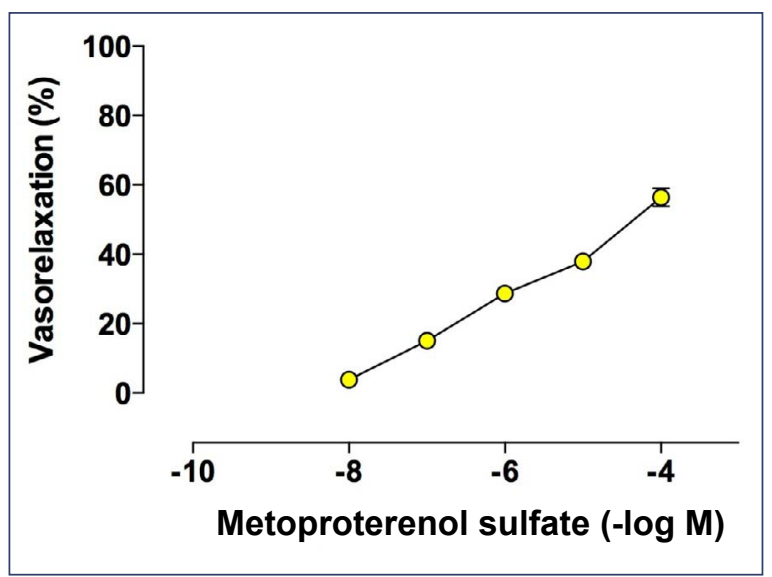

FIGURE 2. The dose-response curve for radial artery graft

Relaxation response was formed in the ITA at a rate of $40.49 \% \pm 13.52$ by adding metaproterenol sulfate with the cumulative method. By rating this relaxation to submaximal contraction, the relaxation dose-response curves were created for the ITA (Figure 1). With a similar method, the relaxation response in the RA was determined to be at a rate of $28.41 \% \pm 9.08$. The dose-response curve that was prepared for the RA graft is given in Figure 2 . In the statistical work that was done by comparing the relaxation values between the ITA grafts and RA grafts, it was observed that there was no significant difference between the efficacy of metaproterenol sulfate on these two grafts ( $p>0.05)$.

The rate of the relaxation that was caused in the SV as a response to metaproterenol sulfate that was added with the cumulative method was $23.87 \% \pm 8.36$. The dose-response curve that was created for the SV graft is given in Figure 3. In the statistical work that was done by comparing 


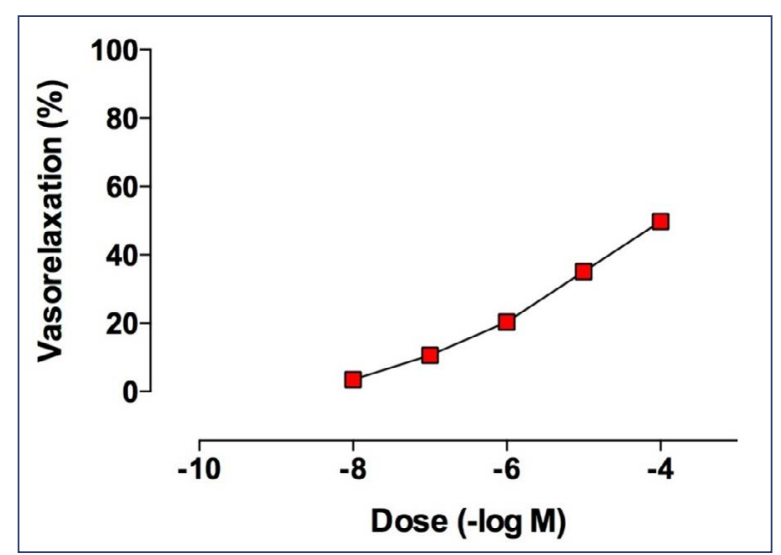

FIGURE 3. The dose-response curve for saphenous vein graft

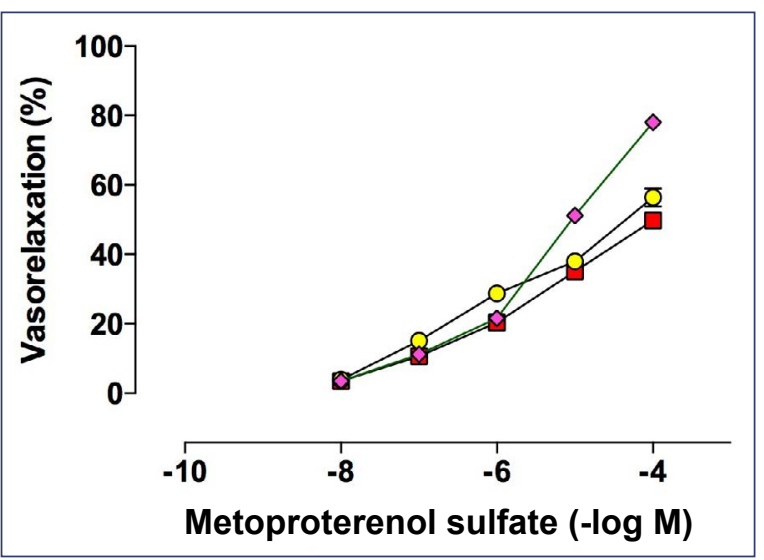

FIGURE 4. Comparison of the relaxation curves for in-vitro treatment with metaproterenol sulfate of internal thoracic artery, radial artery and saphenous vein grafts

the relaxation values among the SV grafts, ITA and RA grafts, it was determined that the efficacy of metaproterenol sulfate in the SV grafts was significantly lower when compared with the ITA and RA grafts $(p<0.05)$ (Figure 4).

\section{DISCUSSION}

Cardiac surgery has rapidly improved in the past 5 decades. The CABG surgery, which was mostly carried out with SV grafts, was preferred after 1980s because of the better long-term effects of the arterial grafts. The purpose is to provide adequate bloodflow to the ischemic area in the heart in bypass operations, which are used widely in our present day. The patency rates of autogenous grafts that are used for this purpose are related directly to the quality of life of the patient and the success of the CABG surgery. The patency rates in autogenous grafts are related closely with the damage on the endothelium during the removal process, and with the vasodilator agents employed in the postoperative period. The grafts that are used mostly in CABG operations are the ITA, RA and SV grafts [10, 11]. The grafts used in our study were the ITA, SV and RA grafts in line with the literature.

The idea that graft vasospasm might occur during $C A B G$ operations, and that this vasospasm might occur more in the RA caused that some surgeons had worries in this respect, which has become an important problem in the agenda [12]. The vasospasm in 'by-pass' grafts is associated with the damage to the vessel wall during removal and implantation. It is already known that the vasospasm is less in venous grafts. In studies conducted with SV grafts, the reason for this was claimed to be the extremely low- or even none- basal production or release of nitric oxide [13]. In arterial grafts, it was shown in previous studies that the nitric oxide release was higher than that in the venous grafts; and for this reason, the patency durations were longer. However, the thing that is important here is that if maximum care is not given during graft removal, nitric oxide production will decrease, and patency rates because of vasospasm will also decrease [14]. One of the most important reasons for early graft failure is the vasospasm [15]. Although the exact mechanism of vasospasm has not yet been clarified, ischemia, hypoxia and vasoconstrictor agents play important roles in the vasospasm mechanism. In addition, the increase in the surgical manipulation and vascular smooth muscle hyperactivity, biochemical and molecular factors as well as other factors [16], such as physical and pharmacological stimuli, are held responsible for this. It is possible that vasospasm occurs together with one or more of these factors [17]. As a result, perioperative morbidity, postoperative myocardial insufficiency and death may occur [18]. For this reason, the search has started for an agent that might prevent vasospasm. The effects of vasodilation agents on arterial grafts depend on the reason of vasoconstriction. If contraction is caused by potassium, which is a depolarizing agent, nifedipine and other calcium-channel antagonists are highly effective in achieving relaxation. The reason for this is that the depolarizing agent potassium causes contraction by ensuring that the calcium-mediated calcium channels are blocked by calcium antagonists. However, it is less effective in preventing the receptor-mediated contraction. For the first time in 1971, Green et al. reported that pa- 
paverine might be employed for this purpose; however, the search for other agents continued because it was not suitable for systemic use [3]. Papaverine has an effect on expanding blood vessels through multiple mechanisms of action, and is a non-specific vasodilator which is generally used topically. It is not suitable for systemic use because of its hypotension effect. It shows its real effect mechanism by increasing the intracellular cGMP level with phosphodiesterase inhibition [19]. It also acts by inhibiting the calcium intake to the cell and the secretion of calcium that is stored in the cytosol [19]. Thanks to this characteristic, it has been argued that it caused vasodilatation at a sufficient level in arterial grafts; and it is still used for this purpose in our present time [20]. The most important problem about the local use of papaverine is that it has a strong acidic structure. It was determined that it causes damage to the endothelial structure because of its strong acidic structure. While its topical application on adventitia layer is effective, its intraluminal use must be avoided because it might harm the endothelial structure. Nilia et al. reported that vasodilator agents might be required right after the removal of the graft [21]. Chanda and Canver reported in their studies that was conducted in 2001 that nitroglycerin might be employed in addition to agents like papaverine, nifedipine, verapamil, diltiazem that are all employed as vasodilator agents [22]. For this reason, organic nitrates such as nitroglycerin and sodium nitroprusside are currently used in CABG surgery. The mechanisms of action are known to increase the intracellular cGMP levels via the activation of guanylate cyclase in vascular smooth muscle cells depending on NO release. As a result, the levels of cytosolic calcium decreases, and relaxation occurs in the smooth muscle cells. In several studies that were conducted on arterial grafts, it was proven that they are effective vasodilators [23]. Among the calcium antagonists, which are divided into 3 groups according to their chemical characteristics, the calcium antagonist that has the weakest effect is known as the diltiazem [24]. As nifedipine, which is a more potent agent, does not have any intravenous form, verapamil and diltiazem are still being used [25]. Metaproterenol sulfate, which is one of the drugs that are employed in the management of hypertension, which appears before us during and after CABG surgeries, activates the adenylate cyclase, and provides dilatation by increasing the CAMP. However, no studies have been conducted on the ef- fects of this drug on grafts. Selective beta-mimetic effective metaproterenol sulfate might accelerate the atrioventricular conduction, and increase the cardiac outflow, and therefore cause tachycardia and dilatation of coronary arteries. In our study, relaxation response was obtained in all grafts with metaproterenol sulfate. Among these grafts, the highest relaxation response was obtained with the IMA graft, and the lowest relaxation response was observed in the SV graft.

\section{Study limitations}

The present study of ours has several limitations. The first limitation is the issue of whether the maximum relaxation that occurred due to metaproterenol sulfate because of high nitric oxide release in the ITA grafts mentioned in previous studies would be referred only to this drug or to the excessively-released nitric oxide. There is a need for studies at receptor level that will be conducted with endothelium and in de-endothelized fashion to clarify this issue. Aside from these, the limited number of patients, and the fact that the study was a single-centered one are other limitations of the present study.

\section{CONCLUSIONS}

In the present study, when the relaxation rates that were formed on the ITA, RA and SV grafts after maximal contraction with the addition of metaproterenol sulfate with Cumulative Method was considered, it was concluded that the risk of developing vasospasm was low in all three grafts when metaproterenol sulfate is used in intraoperative and postoperative periods. However, in the long-term, this made us consider that better graft patency rates might be obtained. Multicenter in-vivo studies with larger patient groups are needed to support our findings.

Funding sources: No funding was received.

Conflict of interest: All authors declare that they have no conflict of interest.

\section{REFERENCES}

1. Ulusoy N, Yaymacı B, Kırali K, et al. ve ark. Femoral arterin lateral sirkumfleks dalının potansiyel bir arteriyel greft olarak morfometrik özellikleri. Türk Göğüs Kalp Damar Cer Derg. 2001; 9: 145-8.

2. Acar $C$, Jebara VA, Portoghese $M$, et al. Revival of the radial artery for coronary artery bypass grafting. Ann Thorac Surg. 1992; 54(4): 
652-9; discussion 659, doi: 10.1016/0003-4975(92)91007-v, indexed in Pubmed: 1358040.

3. Green GE. Rate of blood flow from the internal mammary artery. Surgery. 1971; 70(6): 809-813, indexed in Pubmed: 5124663.

4. Mannacio V, De Vita A, Antignano A, et al. Y grafts with the left internal mammary artery and radial artery. Mid-term functional and angiographic results. Cohort study. Int J Surg. 2014; 12(9): 952-957, doi: 10.1016/j.ijsu.2014.07.008, indexed in Pubmed: 25053131.

5. Conkbayır I, Yanık B, Özkanlı B, et al. Radyal arterin greft olarak çıkarılması öncesi elin renkli Doppler US ile değerlendirilmesi. Tanısal ve Girişimsel Radyoloji 2003;9:377-81.

6. Mills $\mathrm{NL}$, Dupin $\mathrm{CL}$, Everson $\mathrm{CT}$, et al. The subscapular artery: an alternative conduit for coronary bypass. J Card Surg. 1993; 8(1): 66-71, doi: 10.1111/j.1540-8191.1993.tb00576.x, indexed in Pubmed: 8422491.

7. Sönmez B, Arbatlı H, Demirsoy E, Yağan N, Yılmaz O, Arpaz M. Koroner arter hastalı̆ının cerrahi tedavisi. Duran E (editör). Kalp ve damar cerrahisinde. Birinci baskı. İstanbul: Çapa Tıp Kitabevi; 2004. s.1355-93.

8. He GW, Yang CQ. Comparison among arteriyal grafts and coronary artery. J Thorac Cardiovasc Surg. ; 1995: 707-15.

9. H.M. Reppy, W.D. Hail, J.B. Kostis, R.R. Townsend, A. Peng, M. Sirgo. Am J Med, 1994 Jan. ; 96: 77-86.

10. Cho KR, Kim JS, Choi JS, et al. Serial angiographic follow-up of grafts one year and five years after coronary artery bypass surgery. Eur J Cardiothorac Surg. 2006; 29(4): 511-516, doi: 10.1016/j. ejcts.2005.12.026, indexed in Pubmed: 16439151.

11. NEZICD, KNEZEVICA, MLLOJEVIC $P$, et al. The fate of the radial artery conduit in coronary artery bypass grafting surgery. European Journal of Cardio-Thoracic Surgery. 2006; 30(2): 341-346, doi: 10.1016/j.ejcts.2006.05.012.

12. Gabe E, Figal J, Wisner J, et al. Radial artery graft vasospasm. European Journal of Cardio-Thoracic Surgery. 2001; 19(1): 102-104, doi: 10.1016/s1010-7940(00)00601-1.

13. Sellke FW, Boyle EM, Verrier ED. Endothelial cell injury in cardiovascular surgery: the pathophysiology of vasomotor dysfunction. Ann Thorac Surg. 1996; 62(4): 1222-1228, doi: 10.1016/0003-4975(96)00538-3, indexed in Pubmed: 8823128.

14. Hata $M$, Shiono $M$, Orime $Y$, et al. Clinical results of coronary artery bypass grafting with use of the internal thoracic artery under low free flow conditions. J Thorac Cardiovasc Surg. 2000; 119(1): 125-129, doi: 10.1016/s0022-5223(00)70226-1, indexed in Pubmed: 10612770.

15. Wackenfors A, Ingemansson R, Malmsjö M. Endothelin receptors in endothelium-denuded human coronary artery bypass grafts and coronary arteries. Ann Thorac Surg. 2003; 75(3): 874-881, doi: 10.1016/s0003-4975(02)04637-4, indexed in Pubmed: 12645710.

16. Tsuda A, Tanaka $K A$, Huraux $C$, et al. The in vitro reversal of histamine-induced vasodilation in the human internal mammary artery. Anesth Analg. 2001; 93(6): 1453-9, table of contents, doi: 10.1097/00000539-200112000-00020, indexed in Pubmed: 11726422.

17. Liu MH, Floten HS, Furnary AP, et al. Effects of potassium channel opener aprikalim on the receptor-mediated vasoconstriction in the human internal mammary artery. Ann Thorac Surg. 2001; 71(2): 636-641, doi: 10.1016/s0003-4975(00)02249-9, indexed in Pubmed: 11235720.

18. He GW, Buxton BF, Rosenfeldt $F$, et al. Pharmacologic dilatation of the internal mammary artery during coronary bypass grafting. J Thorac Cardiovasc Surg. 1994; 107(6): 1440-1444, indexed in Pubmed: 8196385.

19. Huddart $H$, Saad KH. Papaverine-induced inhibition of electrical and mechanical activity and calcium movements of rat ileal smooth muscle. J Exp Biol. 1980; 86: 99-114, indexed in Pubmed: 7400753.

20. Fabricius $A M$, Oser $A$, Diegeler $A$, et al. Endothelial function of human vena saphena magna prepared with different minimally invasive harvesting techniques. Eur J Cardiothorac Surg. 2000; 18(4): 400-403, doi: 10.1016/s1010-7940(00)00549-2, indexed in Pubmed: 11024375.

21. Nili M. Preparation of the internal thoracic artery by vasodilator drugs: is it really necessary? A randomized double-blind placebo-controlled clinical study. European Journal of Cardio-Thoracic Surgery. 1999; 16(5): 560-563, doi: 10.1016/s1010-7940(99)00308-5.

22. Chanda J, Canver $C$. Reversal of preexisting vasospasm in coronary artery conduits. The Annals of Thoracic Surgery. 2001; 72(2): 476-480, doi: 10.1016/s0003-4975(01)02799-0.

23. He GW, Yang CQ. Use of verapamil and nitroglycerin solution in preparation of radial artery for coronary grafting. The Annals of Thoracic Surgery. 1996; 61(2): 610-614, doi: 10.1016/0003-4975(95)00920-5.

24. He GW, Yang CO, Gately $H$, et al. Potential greater than additive vasorelaxant actions of milrinone and nitroglycerin on human conduit arteries. Br J Clin Pharmacol. 1996; 41(2): 101-107, doi: 10.1111/j.1365-2125.1996.tb00166.x, indexed in Pubmed: 8838435.

25. He GW, Liu ZG. Comparison of nitric oxide release and endothelium-derived hyperpolarizing factor-mediated hyperpolarization between human radial and internal mammary arteries. Circulation. 2001; 104(12 Suppl 1): I344-I349, doi: 10.1161/hc37t1.094930, indexed in Pubmed: 11568080. 